\title{
Archéopages
}

Archéopages Archéologie et société

\section{Une maison mixte médiévale à Roissy-en-France}

\author{
Jean-Yves Dufour
}

\section{OpenEdition}

Journals

Édition électronique

URL : https://journals.openedition.org/archeopages/307

DOI : 10.4000/archeopages.307

ISSN : 2269-9872

\section{Éditeur}

INRAP - Institut national de recherches archéologiques préventives

\section{Édition imprimée}

Date de publication : 1 mai 2013

Pagination : 67

ISSN : $1622-8545$

\section{Référence électronique}

Jean-Yves Dufour, « Une maison mixte médiévale à Roissy-en-France », Archéopages [En ligne], 35 |

10/2012, mis en ligne le 01 octobre 2014, consulté le 05 février 2022. URL : http://

journals.openedition.org/archeopages/307 ; DOI : https://doi.org/10.4000/archeopages.307 

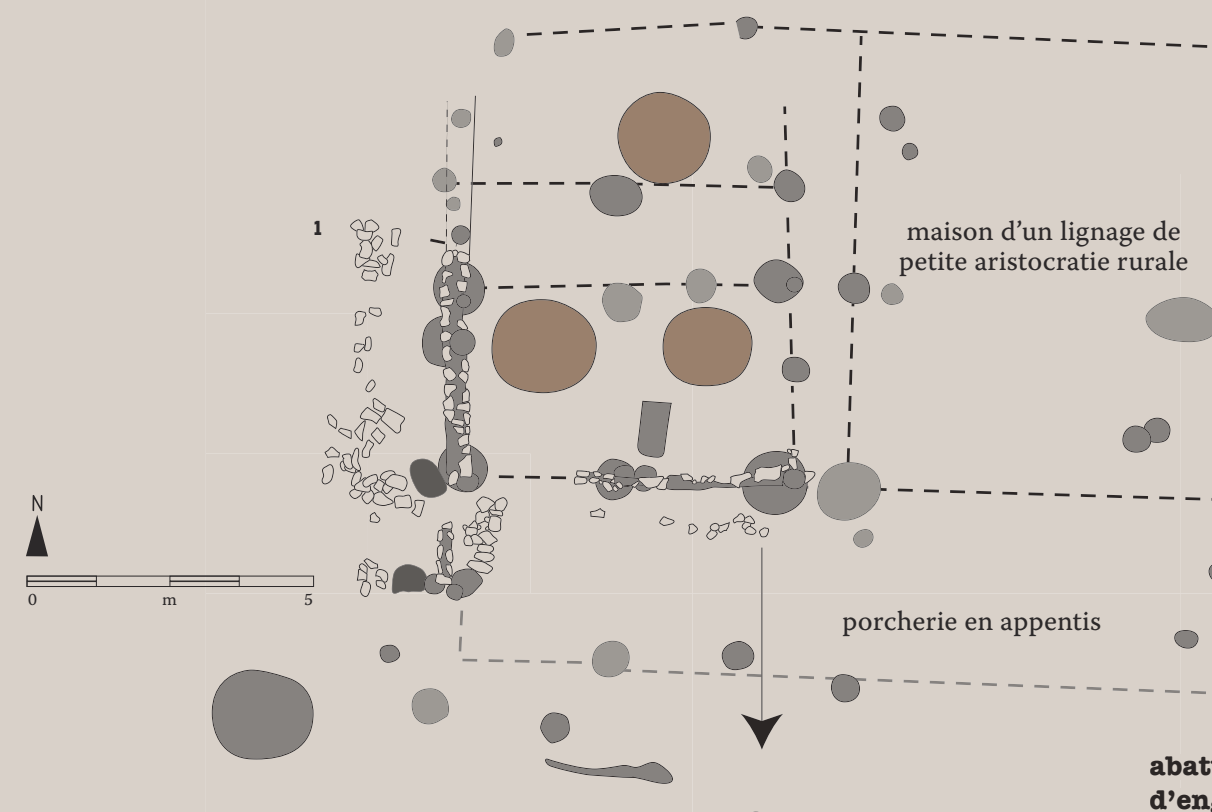
petite aristocratie rurale
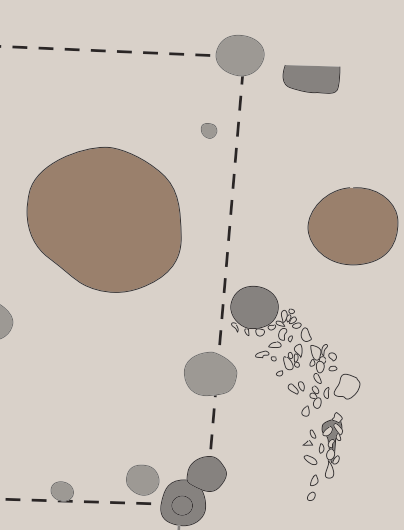

\section{Une maison}

\section{mixte}

médiévale

à Roissy-

\section{en-France}

Jean-Yves Dufour ${ }^{I n r a p, ~}, U_{M R} 7041$ «Archéologie et Sciences de l'Antiquité »
Des vestiges datés entre la seconde moitié du $\mathrm{xIr}^{\mathrm{e}}$ siècle et le premier quart du xIIr $^{\mathrm{e}}$ siècle, sur le site du château de Roissy-en-France (Val-d'Oise), ont été identifiés grâce à des méthodes géoarchéologiques. Leur interprétation s'est fondée sur une étude interdisciplinaire (données archéologiques et données textuelles). La fouille a concerné le flanc sud d'une maison à hall ouvert de la seconde moitié du xrre siècle, bien délimitée par des solins et de nombreux silos. Fllle a révélé une zone sous appentis, composée d'un écheveau de couches en pente vers le sud entremêlées de creusements. L'analyse chimique du secteur prouve le caractère organique de ces couches, définies par un taux élevé de carbone organique, et un autre, très élevé, de phosphore total. La micromorphologie témoigne de la présence de déjections et de traces de piétinement animal (étude Cécilia Cammas, Inrap, AgroParisTech). Plus de $80 \%$ des phytolithes sont des graminées. Celles-ci n'ont subi aucun traitement anthropique. L'absence de réelle litière végétale et la présence de phytolithes de bois (sphéroïdes) peuvent évoquer un élevage sur claies (étude Pascal Verdin, Inrap, CEPAMI).

Un jeune cochon complet, trouvé en connexion dans un silo au nord de la maison, permet d'attester un élevage sur place. L'étude de la faune montre que la totalité du troupeau de porcs était abattue après une ou deux saisons d'engraissement (étude Stéphane Frère, Inrap, CRAVO).

La position du bâti, accolé à la maison, correspond a priori plutôt à une écurie. Pourtant, l'hypothèse d'une porcherie peut être entièrement expliquée par la théorie de la construction agricole qui comprend des variantes pour chaque type de logement à bétail. De fait, seuls quatre auteurs du début du xx ${ }^{\mathrm{e}}$ siècle. recommandent d'éloigner la porcherie des habitations alors que cette idée n'apparaît dans aucun manuel auparavant. L'acceptation olfactive du porc est strictement culturelle et ne semble pas gêner les hommes avant le fort développement de l'hygiène à la fin du $x x^{e}$ et au début du $x^{e}$ siècle.

« Lorsque l'économie des cochons est bien réglée, et que l'on a en abondance de la nourriture en hiver, il sera toujours très avantageux d'exiger deux portées par année. " (Thaër, 1831, p. 599) Afin de faciliter la nourriture des cochons en hiver, la porcherie est en relation avec le bâtiment d'habitation. Si l'exposition n'est pas présentée comme une priorité pour les porcheries, trois auteurs recommandent cependant de les orienter au midi. La construction en appentis est fréquente pour les toits à porcs, comme en témoignent les manuels et nos observations dans diverses fermes franciliennes. Si le sol en dur est recommandé par la grande majorité des auteurs modernes, il n'est pas exclusif: « en France l'estable à pourceaux est planchée avec de gros aix percés au fond comme crible : et ce plancher, eslevé d'un bon pied sur terre, par ces trous vide l'urine des pourceaux, dont leur litière demeure sèche. " (Olivier de Serres, 1600, Quatriesme Lieu, ch. XV) 